\title{
Endocrinal Misbalance in Acne Patients with Postacne Signs
}

\section{Lisniak AP* and Bardova KO}

Shupyk National Medical Academy of Postgraduate Education, Ukraine

Research article

Volume 5 Issue 2

Received Date: April 11, 2020

Published Date: May 18, 2020

DOI: $10.23880 /$ cdoaj-16000212

*Corresponding author: Anna Lisniak, P.L. Shupyk National Medical Academy of Postgraduate Education, Ukraine, Tel: +971506743634; Email: dr.annalisniak@gmail.com

\section{Abstract}

Objectives: Endocrine factors influence acne and it can also influence postacne signs formation. Therefore study of hormonal levels in acne patients with postacne signs formation is very important. The aim was to study levels of hormones and estimate changes of each studied hormone.

Methods: 102 female out-patients from Kyiv city dermatovenereologic hospital and other bases of the department of dermatovenereology with different clinical forms of acne were examined. Clinical and hormonal tests were done.

Results: $52.94 \%$ acne patients had different hormonal misbalances. The most typical changes were increased levels of prolactin and decreased levels of progesterone. The most typical changes in subgroup of acne patients with comorbidities were increased levels of $17 \alpha$-hydroxyprogesterone and prolactin.

Conclusions: Hormonal misbalance can lead to late acne and more severe acne manifestations including postacne signs. Additional endocrinologic conditions can increase such an influence. Correction and control of endocrinologic disbalance can improve efficacy of acne treatment and prevent formation of postacne signs.

Keywords: Postacne; Hypertrichosis; Prolactin; Endocrinologic disbalance

\section{Introduction}

According to Ukrainian and foreign literature the interest to the problem of acne and postacne signs is growing. Because of wide spread of acne and postacne it is important for modern dermatology and esthetic medicine to study mechanisms of its development [1-4].

There are several methods of medical correction of postacne signs (topical treatment, injections and surgery) but none of them satisfy patients or doctors and guarantee good cosmetic effect [2,5-12]. Development of new methods of postacne treatment is actual. It is important to study different aspects of pathogenesis of postacne for that. Nevertheless, there are several modern explanations of acne and postacne formation but it is multifactorial problem and all these factors have to be investigated. Typically acne disappears without any signs but in about $40 \%$ of acne patients postacne is present. It happens because of evolution of acne rash elements. Scars, post inflammatory erythema and dishromia belong to postacne signs. Duration of acne correlated with postacne signs formation. Global alliance acne treatment informed that duration of acne, deep inflammatory skin rash elements, and traumatization by patients and inadequate treatment are main reasons of postacne signs development [13]. Erythema and pigmentations are results of epidermal changes and scars are results of dermal traumatization. Hypertrophic or celoid scars are formed in case of excessive synthesis of connective tissue. It is most typical on the breast, between scapula and more rear on lower parts of jaws. But other types of scars are more frequent on the face. Atrophic scars are more typical for face than for extrafacial regions.

Endocrine factors influence acne and it can also influence postacne signs formation. Therefore study of hormonal levels in acne patients with postacne signs formation is very important.

The aim was to study levels of hormones and estimate changes of each studied hormone. 


\section{Clinical Dermatology Open Access Journal}

\section{Methods}

Patients with acne and postacne signs from Kyiv city dermatovenereologic hospital and other bases of the department of dermatovenereology were involved. In total 102 female out-patients with different clinical forms of acne were examined. All patients had clinical and laboratory examinations. Age of patients was 18-44 years old. Majority of patients were 20-30 years old.

The following laboratory tests were done for all patients:

- Luteinizing hormone

- Follicle-stimulating hormone

- Prolactin

- Thyroid-stimulating hormone

- $\quad 17 \alpha$-Hydroxyprogesterone $(170 H)$

- Dihydrotestosterone

- Testosterone

- Sex hormone binding globulin

- Dehydroepiandrosterone sulfate

- Free testosterone index

- Estradiol (E2)

- Progesterone

Statistic programs STATISTICA 10.0 En and Medstat were used. For statistical significance the value of $p<0.05$ was used.

\section{Results and Discussion}

From 102 studied women with acne about $90 \%$ had level 2 of acne severity. 17 patients also had hypertrichosis and 4 patients had diffuse alopecia. One patient had autoimmune thyroiditis and another one myasthenia.

$52.94 \%$ patients had different hormonal misbalances (Table 1). The most typical changes were increased levels of prolactin $(\mathrm{n}=21)$ and decreased levels of progesterone $(n=23)$.

Only one patient with acne and hypertrichosis had all normal tests results. It showed that coexistence of hypertrichosis can increase hormonal misbalance and probably influence the course of acne and postacne signs. The most typical changes in this subgroup of acne patients were increased levels of $17 \alpha$-hydroxyprogesterone and prolactin. In patients without comorbidities the most frequent change was decrease of progesterone (Table 1).

Hormonal misbalance can lead to late acne and more severe acne manifestations including postacne signs. Additional endocrinologic conditions can increase such an influence.

Correction and control of endocrinologic disbalance can improve efficacy of acne treatment and prevent formation of postacne signs.

\begin{tabular}{|c|c|c|c|}
\hline Age & Hormonal changes & Acne severity grade & Comorbidities \\
\hline 18 & Prolactin, 170 H, Dihydrotestosteron & 1 & Hypertrichosis \\
\hline 24 & Prolactin, $170 \mathrm{H}$ & 2 & \\
\hline 25 & Progesterone & 2 & \\
\hline 18 & Progesterone & 3 & Myasthenia \\
\hline 23 & Progesterone & 2 & Hypertrichosis \\
\hline \multirow{2}{*}{28} & 170 , Prolactin, & Hypertrichosis \\
\hline 29 & Testosterone & & \\
\hline 23 & Progesteron & 2 & \\
\hline 30 & Progesterone & 1 & \\
\hline 33 & Dehydroepiandrosterone sulfate, Progesterone & 2 & Hypertrichosis \\
\hline 30 & $170 H$, Sex hormone binding globulin & 3 & \\
\hline 30 & Prolactin & 2 & \\
\hline 20 & Dehydroepiandrosterone sulfate, Progesterone & 2 & \\
\hline 27 & Estradiol & & \\
\hline
\end{tabular}




\section{Clinical Dermatology Open Access Journal}

\begin{tabular}{|c|c|c|c|}
\hline 30 & Sex hormone binding globulin & 1 & Diffuse alopecia \\
\hline 22 & Progesterone & 2 & \\
\hline 25 & Prolactin, $170 H$, Progesterone & 2 & \\
\hline \multirow{2}{*}{22} & Prolactin & \multirow{2}{*}{2} & \\
\hline & Progesterone & & \\
\hline 28 & Prolactin & 2 & Hypertrichosis \\
\hline 28 & $17 \mathrm{OH}$ & 2 & \\
\hline 18 & Progesterone & 2 & \\
\hline 31 & Prolactin & 2 & \\
\hline 26 & $\begin{array}{c}\text { Prolactin, Testosterone, } 17 \mathrm{OH} \text {, Sex hormone binding } \\
\text { globulin }\end{array}$ & 2 & \\
\hline 18 & $17 \mathrm{OH}$, Testosterone & 2 & \\
\hline 32 & Prolactin & 2 & Diffuse alopecia \\
\hline 34 & Sex hormone binding globulin & 2 & \\
\hline 22 & Prolactin, Estradiol & 2 & \\
\hline \multirow{2}{*}{36} & Sex hormone binding globulin, Dihydrotestosterone, & \multirow{2}{*}{1} & \multirow{2}{*}{ Diffuse alopecia } \\
\hline & Progesterone & & \\
\hline 18 & $17 \mathrm{OH}$, Testosterone & 2 & \\
\hline 41 & Estradiol, Progesteron & 2 & \\
\hline 21 & Dehydroepiandrosterone sulfate, Progesterone & 2 & \\
\hline 25 & Prolactin & 2 & \\
\hline \multirow{2}{*}{21} & Prolactin & \multirow{2}{*}{2} & \\
\hline & Progesterone & & \\
\hline 26 & Progesterone & 2 & \\
\hline 29 & Prolactin & 2 & \\
\hline 23 & Progesterone & 1 & \\
\hline \multirow{2}{*}{20} & Prolactin & \multirow{2}{*}{2} & \multirow{2}{*}{ Hypertrichosis } \\
\hline & Progesterone & & \\
\hline 29 & $17 \mathrm{OH}$ & 2 & \\
\hline 23 & $\begin{array}{c}17 \mathrm{OH}, \text { Sex hormone binding globulin, } \\
\text { Dehydroepiandrosterone sulfate }\end{array}$ & 2 & Hypertrichosis \\
\hline 25 & $\begin{array}{l}\text { Prolactin, Progesterone, Testosterone, } \\
\text { Dehydroepiandrosterone sulfate }\end{array}$ & 2 & Hypertrichosis \\
\hline 18 & Testosterone, Progesterone & 2 & Diffuse alopecia \\
\hline 20 & Dehydroepiandrosterone sulfate & 2 & Hypertrichosis \\
\hline 18 & Testosterone & 2 & \\
\hline 18 & $\begin{array}{l}\text { Testosterone, Dehydroepiandrosterone sulfate, Thyroid- } \\
\text { stimulating hormone, Progesterone }\end{array}$ & 2 & Hypertrichosis \\
\hline 38 & $17 \mathrm{OH}$ & 2 & Hypertrichosis \\
\hline 35 & Prolactin, Testosterone & 2 & \\
\hline 20 & Prolactin & 2 & \\
\hline
\end{tabular}




\section{Clinical Dermatology Open Access Journal}

\begin{tabular}{|l|c|c|c|}
\hline 18 & Dehydroepiandrosterone sulfate, Progesterone & 2 & Hypertrichosis \\
\hline 20 & Progesterone & 2 & 2 \\
\hline 25 & $17 \mathrm{OH}$ & 2 & $\begin{array}{c}\text { Autoimmune } \\
\text { thyroiditis }\end{array}$ \\
\hline 41 & Thyroid-stimulating hormone, $170 \mathrm{H}$ & 2 & \\
\hline 28 & Prolactin & 2 & Hypertrichosis \\
\hline 25 & Testosterone & 2 & \\
\hline 25 & $\begin{array}{c}\text { Prolactin, 170H, Dehydroepiandrosterone sulfate, Sex } \\
\text { hormone binding globulin }\end{array}$ & & \\
\hline
\end{tabular}

Table 1: Hormonal changes in acne patients.

\section{References}

1. Soliman YS, Horowitz R, Hashim PW, Nia JK, Farberg AS, et al. (2018) Update on acne scar treatment. Cutis. 102(1): 21;25;47;48.

2. Goodman GJ (2000) Postacne scarring: a review of its pathophysiology and treatment. Dermatol Surg 26(9): 857-871.

3. Bardova KO (2015) Some Aspects of Scar Treatment. Dermatologia ta venereologia 1: 56-62.

4. Kolcheva PA, Kolcheva LS, Kruglova OV (2015) Physiotherapeutic methods in the treatment of acne and postacne. Fizioterapevt 3: 31-37.

5. Geynits AV, Kiani SA, Okushko S (2013) Application of combined epidermal and dermal fractional ablation in the treatment of atrophic scars in the supply chain. Vestnik esteticheskoy meditsiny 4: 58--77.

6. Kachuk, Yu V ( 2014) Modern possibilities of correction of supply chain. Zhurnal dermatovenerologii ta kosmetologiï im. M.O.Torsuєva 1: 96-98.

7. Kolcheva PA, Zhukova OV (2015) Correction of supply by the method of exposure to radiofrequency fractional micrneedles. Fizioterapevt 5: 15-20.
8. Lazarenko NN, Supova MV, Trunova OV (2015) Microcurrent therapy in the treatment of patients with a supply. topical issues of modern medicine. Fizioterapevt 1: 8-10.

9. Urakova DS, Pozdeeva EV (2016) Erbium laser in correction supply box. Apparatnaya kosmetologiya 2: 40-43.

10. Cachafeiro T, Escobar G, Maldonado G (2016) Comparison of Nonablative Fractional Erbium Laser 1,340 nm and Microneedling for the Treatment of Atrophic Acne Scars: A Randomized Clinical Trial. Dermatol Surg 42: 232-241.

11. Erbağci Z, Akçali C (2000) Biweekly serial glycolic acid peels vs. long-term daily use of topical low-strength glycolic acid in the treatment of atrophic acne scars. Int J Dermatol 39(10): 789-794.

12. Zawar VP, Agarwal M, Vasudevan B (2015) Treatment of Postinflammatory Pigmentation Due to Acne with Q-Switched Neodymium-Doped Yttrium Aluminum Garnet In 78 Indian Cases. J Cutan Aesthet Surg 8(4): 222-226.

13. Thiboutot DM, Dréno B, Abanmi A, Alexis AF, Araviiskaia E, et al. (2018) Practical management of acne for clinicians: An international consensus from the Global Alliance to Improve Outcomes in Acne. J Am Acad Dermatol 78(2): S1-S23.e1. 